\title{
Folkloorist kirjandusse ehk variatsioonid Rainisega läti ja eesti kultuuris $^{1}$
}

\author{
Anneli Mihkelev \\ Tallinna Ülikooli humanitaarteaduste instituudi vanemteadur \\ anneli.mihkelev@tlu.ee
}

\begin{abstract}
Teesid: Rainis ${ }^{2}$ (1865-1929) on üks kuulsamaid läti modernistlikke kirjanikke, kelle tööd esindavad möödunud sajandi alguse, keerulise ja pöördelise ajaloolise perioodi kultuuri. Rainise teosed sisaldavad motiive, mis on tõlgitud teistest kultuuridest, sh eesti kultuurist. Oma töödes tõlkis ning kohandas ta neid motiive omaenda kultuurile vastavaks, kultuuritõlke kaudu kandusid erinevad motiivid ühest kultuurist teise. Artiklis käsitletakse Rainise näidendites leiduvat folkloorist pärit materjali ning selle seost ilukirjandusega.
\end{abstract}

Märksõnad: folkloorsed motiivid, kultuuritõlge, kultuuriülekanne, läti kirjandus, modernism, sümbolism

Läti ja eesti kultuurikontaktid on eksisteerinud sajandeid. 13. sajandist pärit Henriku Liivimaa kroonika on üks vanemaid dokumente, kus kahe naaberrahva suhteid kirjeldatakse. Need pole alati olnud sõbralikud, kuid ometi leidub neis kirjeldustes jälgi, kultuurilisi laene ja variatsioone kahe maa folkloorist, kust need omakorda on leidnud tee ilukirjandusse ning kultuuri laiemalt. Niisugused kultuurilised kontaktid saavad alati alguse retseptsioonist, vastuvõtust, kuidas teist kultuuri või täpsemalt kultuuriteksti uues kultuurikontekstis vastu võetakse. Olulist rolli mängib siin mõistagi tõlge. Läti kirjanduse lugu Eestis on tõlkimise ja vastuvõtu lugu. Tõlke ja retseptsiooni piirid on seejuures hägusad ja liikuvad, sõltuvad kontekstist. Peeter Torop on artiklis "Tõlge ja/ kui retseptsioon" juhtinud tähelepanu sellele, et tõlge ise on uues kultuuris retseptsioon ning tõlke positsioon võõras kultuuris sõltub paljudest teguritest (Torop 1999: 20-21).

Käesolevas artiklis on vaatluse alla võetud läti ühe kuulsaima luuletaja, tõlkija ja draamakirjaniku Rainise (1865-1929) tööd, sest need esindavad möödunud sajandi alguse, ühe keerulisema ja pöördelisema ajaloolise perioodi kultuuri. Eesti kultuurile ja kirjandusele mõeldes võiks Rainist võrrelda Gustav Suitsuga (1883-1956). Suits oli küll noorem, aga mõlemad kirjanikud olid poliitiliselt aktiivsed ja seotud vasakpoolse sotsiaaldemokraatliku liikumisega, mõlemad 
olid uuendusmeelsed ning vaatasid Euroopas levinud modernistlike suundade poole (vt Lange 2002: 24). Rainise ja Gustav Suitsu 20. sajandi alguse luulest on lähemalt kirjutanud Eva Egalāja-Kristsone, kes juhib tähelepanu sümbolismi mõjule mõlema luuletaja loomingus (Egalāja-Kristsone 2009: 52-53). Rainis oli mõjutatud vene sümbolismist, täpsemalt oli luuletaja Konstantin Balmont (1867-1942) see, kellelt pärineb revolutsioonilise päikese sümbol. Rainis kirjutas eksiilis olles võimsa poeemi “Ave Sol!” (1910), lähtudes uue alguse ideest, uue Läti ideest ning isiklikest eksiilikogemustest. Päike sümboliseeris Rainise silmis aastaaegade vaheldumist, looduse igavest ringkäiku, algust ja lõppu, pimedust ja valgust. (Egalāja-Kristsone 2009: 56-57) Päike, mida Rainis oma poeemis kujutab, on väga võimas, tänu temale toimuvad looduses ja inimeste elus suured nuutused. Tähelepanuväärne on see, kuidas Rainis on mänginud selles poeemis grammatilise sooga. Päike, mis maailma nii võimasalt kujundab ja muudab, võiks eelduste kohaselt olla meessoost nagu mütoloogiast üldiselt teada, kuid Rainisel ilmub ta kohati lugeja ette naiseliku ilu kehastajana:

Haljas, sinkjas, verev-valge -

Tantsib, sädemeidki pillub.

Pead siis raputab me päike,

Paksud patsid valla vaovad,

Kuldsed juuksed üle ilma.

Nende siidipehmeist lainteist

Valgub soojus musta mulda,

Maapind värahteleb mõnust,

Naeratades avab jälle

Oma tuhat järvesilma,

Ärkab uue õnne ootel.

(Rainis 1965: 94, tlk K. Aben)

Läti keeles on päike naissoost sõna ning folklooris ongi seda kujutatud naisena, Kuud seevastu kujutatakse mehena, kes palub Päikest endale naiseks. Päike on läti folklooris pidevas liikumises ning sellisena kujutab Rainis seda ka oma poeemis. Mõnes kohas on aga Päikest kujutatud maskuliinselt, rasket tööd tegemas ning võitlemas uue elu eest:

Tulist kuumust suurendades,

Kuivast vihast lõkendades,

Seisab päike valges lõõmas,

Varjudeta keset päeva. 
Käised kä̈ritud, ta julgelt

Lükkab punast leegiketast

Üle taeva sinivõlvi.

Alla tilgub higitähti,

Kuldsed haamrid ketast taovad,

Tuleräbu maale langeb,

Üles kerkib musta suitsu,

Tiigisilmad jä̈̈vad kuivaks,

Lohku vaovad soode põsed,

Künkanõlvad pragunevad,

Närbub, kuivab vana rohi,

Kõik, mis kaotand eluvõime.

(Rainis 1965: 109, tlk K. Aben)

Rainis toetub oma luules ja näidendites läti mütoloogiale. Peamine mõte, mida Päike Rainisel sümboliseerib, on vana elu hävimine ja uue loomine, millele Päike kaasa aitab. See kehtib nii looduse kui ka inimühiskonna kohta (EgalājaKristsone 2009: 58-59).

Gustav Suits ja Rainis olid küll väga erinevad kirjanikud, kuid mõneti sarnane tundub olevat nende loomemeetod: haarata ideid ja motiive igalt poolt ümbritsevast ning panna sellest kõigest kokku oma isikupärane stiil, mis toetub nii oma kui ka nn võõrastele kultuuridele (modernismi ja modernsuse arengutest 19. ja 20. sajandi vahetusel vt Calinescu 1987), nagu tegid seda vene sümbolistid või iiri kirjanik William Butler Yeats (1865-1939) ja soome luuletaja Eino Leino (1878-1926). Vähe oluline pole seegi, et ilukirjanduse kaudu tõid nad oma lugejateni tol ajal levinud poliitilisi ideid, mille vastuvõtt sõltus konkreetsest poliitilisest kontekstist.

Rainise revolutsioonilisele tegevusele avaldasid mõju toonane ajaloolis-poliitiline olukord, Vene revolutsioon ja Euroopas levinud marksistlikud vaated. Selles mõttes sarnaneb tema tegevus Noor-Eesti autorite Gustav Suitsu, Friedebert Tuglase jt omaga, kuid Rainisel tuli aktiivse revolutsioonilise tegevuse tõttu märksa rohkem vangis ja asumisel viibida. Seejuures jäi ta kunstnikuna äärmiselt omapäraseks ja originaalseks kirjanikuks, nagu on näha tema eksiilis loodud kirjandusest. Aare Pilv on võrrelnud kodumaa kujutamist kahe autori luules, keskendudes just 1905. aasta sündmustest ajendatud loomingule, Gustav Suitsu esimesele luulekogule "Elu tuli" (1905) ja Rainise kogumikule "Vētras sēja" (Tormikülv, 1905). A. Pilve analüüsist ilmneb, et Rainise luule kannab selgemat sotsiaal-poliitilist sõnumit, Gustav Suitsu luule on aga abstraktsem ning võimaldab mitmekesisemat interpretatsiooni. (Pilv 2009: 66-67) 
Mart Pukits, kes oli 1930. aastatel üks peamisi läti kirjanduse tõlkijaid ja tutvustajaid Eestis, rõhutab 1929. aasta Loomingus ilmunud artiklis kõigepealt ülemöödunud sajandivahetuse pöördelisi momente, millega Rainis oli seotud. Neist vast üks olulisem oli tema tegevus vasakpoolse ajalehe Dienas Lapa toimetajana. Leht avaldas oma ilmumise ajal joonealuseid tõlkeid Euroopa moodsate autorite teostest, nagu Guy de Maupassant, Alexander Kielland, Hermann Sudermann, Anton Tšehhov, Ignati Potapenko jt (Pukits 1929: 1173). Mingil moel saab Läti ajalehe püüdlusi ja tegevust võrrelda veidi hiljem tegutsenud Noor-Eesti tegevusega. Kui Rainis pidi 1895. aastal toimetaja kohalt Miitavisse pagulusse minema, jätkas ta seal tegevust luuletaja ja tõlkijana, kuna advokaadina tal töötada ei lubatud. Rainis oli juba enne tuttav nii leedu kui ka Põhjamaade folkloori ning saksa parimate luuletajate töödega. Muu hulgas tundis ta nii Soome "Kalevalat" kui ka Eesti "Kalevipoega".

Pidevate segavate tegurite tõttu viibis Rainise esimese luulekogu ilmumine. Mart Pukits kirjutab Rainise kaua viibinud esimese luulekogu "Kauged kajastused sinisel õhtul" (1903) kohta järgmist:

See oli tähtis sündmus nii Rainise enese kui ka läti lüürika ajaloos, sest siin ilmnes luuletaja omapärane individualiteet terves selle suuruses ja tugevuses, siit algas uus ajajärk läti luules, kus senini ei oldud midagi sellesarnast nähtud ei ideelises ega esteetilises suhtes. Enne kõike on ses kogus Rainise väljendusvorm uus ja algupärane, ta lauludes leidub vaevalt mõtet, mis tuletaks meelde teist luuletajat. [---] "Kaugetes kajastustes" paneb Rainis enese hoobilt maksma küpse kunstnikuna, kes kuulutab rahvale vabadust ja julgelt liitub võitlejatega. Sügava mõtlejana sulgeb ta oma vormikindlasse salmidesse terve ühiskondliku filosoofia süsteemi ja muudab radikaalselt senise mõttesuuna ja väljendusviisi läti luules. [---] ... kui Rainis kujutabki loodust, siis läbistab ka seda võitlusmõte. Kõneldes sügavast talvest, mõtleb ta sümboolselt ühiskondlikku tardumust. Ootab ta kevadist lumelagunemist, siis igatseb ta poliitilise surve kadumist. Heitlus talve ja kevade vahel tähendab orjastuse ja vabaduse võitlust. (Pukits 1929: 1175-1176)

Niisugune mäng sümbolitega läbib kogu Rainise loomingut alates luulest ja lõpetades tema võimsate ja mitmeid tähenduskihte sisaldavate näidenditega. Sümbolid toimivad Rainise loomingus nii, nagu Juri Lotman on kirjeldanud:

Sümbolis on alati midagi arhailist. Iga kultuur vajab tekstikihistust, mis täidaks archaika funktsiooni. [---] Sümbolite tajumine sellisena pole juhuslik: nende tuumrühm on oma loomult tõesti väga arhailine ja pärineb kirjaeelsest ajastust, mil teatud kindlad (üldjuhul elementaarse 
kujuga) märgid olid kokkukeritud mnemoonilised programmid, mis talletasid tekste ja süžeesid kollektiivi suulises mälus. Sümbolite võime hoida kokkukeritud kujul alles väga mahukaid ja tähendusküllaseid tekste on säilinud. [---] ...sümbol ei kuulu kunagi mingisse ühte sünkroonsesse kultuuriläbilõikesse - alati läbistab ta seda läbilõiget mööda vertikaali, tulles minevikust ja lahkudes tulevikku. Sümboli mälu on alati iidsem kui tema mittesümboolse tekstuaalse ümbruse mälu. (Lotman 1999: 222-223)

See tähendab, et sümbolite tähendused võivad muutuda kontekstist lähtuvalt. Nii on Rainis kasutanud oma luules väga vana Päikese sümbolit, mis tema ajastu kontekstis saavutas hoopis teistsuguse tähenduse kui antiikajal. Ja diakroonilisel liikumisel uude konteksti võivad need pealtnäha arhailised sümbolid luua midagi uut, tekitades Lotmani järgi plahvatusliku momendi:

Kunstifenomeni puhul on võimalik eristada kaht vastupidist tendentsi: tendents korrata juba tuttavat ja tendents luua põhimõtteliselt uut. [---] Arhailise loomingu omapära, mille jälgi me folklooris näeme, ei seisne selle näilises tardumuses, vaid tema esitaja ja kuulaja funktsioonide teistsuguses jaotamises. Folkloori arhailised vormid on rituaalsed. See tähendab, et neil puudub passiivne auditoorium. [---] Seega kujutavad dünaamilised kultuuriprotsessid endast omamoodi pendli võnkumist plahvatusseisundi ja sellise organiseeritusseisundi vahel, mis realiseerub järjepidevates protsessides. Plahvatushetkele on iseloomulik kõigi vastandite samastumine. Erinev esineb samana. See teeb võimalikuks ootamatud põiked täiesti teistsugustesse, ennustamatu organisatsiooniga struktuuridesse. Võimatu saab võimalikuks. Seda hetke kogetakse ajatuna isegi siis, kui see reaalajas vältab pikki ajalõike. (Lotman 2001: 175-179)

\section{Rainis ja Eesti}

Võib öelda, et Rainis on üks kuulsaimaid läti modernistlikke kirjanikke, kelle tööd on Eesti kultuuriga seotud mitmete motiivide vahendusel. Rainise kontaktid Eestiga algasid juba tema lapsepõlves tänu eesti soost Palamuse külas sündinud õpetaja Bernhard Morale, kes polnud mitte ainult õpetaja, vaid ka luuletaja, kes mõjutas selles suunas oma õpilastki. Hiljem need kontaktid jätkusid ja leidsid väljenduse Rainise loomingus. Rainise teosed sisaldavad motiive, mis on tõlgitud teistest kultuuridest, sh eesti kultuurist. Oma töödes tõlkis ja kohandas ta neid motiive omaenda kultuurile vastavaks. Peeter Torop kirjeldab kultuuris toimuvaid tõlkeprotsesse järgmiselt: “Teksti tõlkimisel tekstiks leiab 
aset ka kultuuri tõlkimine kultuuri - seega on keel, tekst ja kultuur nendeks tekstiosadeks, mida võib tähtsuse või suva järgi ritta panna, mida on võimalik üksteise kaudu vahendada või originaalis tuvastatavaid proportsioone tõlkimisel säilitada" (Torop 1999: 22-23). Kultuuri tõlkimise kaudu kanduvad erinevad motiivid ühest kultuurist teise ehk teisisõnu toimub kultuuri ülekanne ehk transformatsioon. Ühtlasi sisaldavad Rainise teosed teiste kultuuride ja tekstide retseptsiooni, sest tõlge algabki retseptsioonist, tõlgitava teksti valikust.

Oma töödes ühendas Rainis eesti ja läti folkloori ning sidus need Euroopa kontekstiga, osutades nii Euroopa rahvaste omavahelistele suhetele. Seejuures kasutas ta folkloorse materjali edasiandmiseks modernismi, täpsemalt sümbolismi keelt: "Tõlgitav tekst, mis on üheaegselt kirjandusloo tekst ja kultuuritekst, millest arusaamine eeldab lugejalt vastavaid eelteadmisi mõlemas keeles, võib jõuda teise kulturi mitme tekstina" (Torop 1999: 23).

Rainise näidendites leidub folkloorist pärit materjali väga erinevates variantides ning lisaks originaaltekstile on nüüdseks tänu paljudele lavastustele lisandunud väga erinevaid tõlgendusi, teisisõnu on tõlgitud tekstid jõudnud vastuvõtvasse kultuuri mitme tekstina. Need tõlgendused interpreteerivad vana folkloorset materjali ning ühtlasi Rainise loodud algset kirjanduslikku teksti. Kõik see loob väga elava kirjandusliku kommunikatsiooni, mis ei piirdu üksnes autori, teose ega lugejaga, vaid on laienenud metakommunikatsiooni tasandile, millest võtab osa palju lugejaid, interpreteerijaid jt kultuuriruumis osalejaid.

Kui Rainis õppis Riia gümnaasiumis, seosed Eestiga jätkusid. Rainis õppis eesti rahvalaule tundma Herderi tööde kaudu ning luges Eesti ajaloost Balthasar Russowi teosest "Chronica der Prouintz Lyfflandt" (Liivimaa kroonika, 1578).

Tugevalt inspireeriv kontakt eesti kultuuriga oli 1887. aastal, mil Riias oli eesti skulptori August Weizenbergi näitus ning Rainis nägi Weizenbergi skulptuure "Koit" ja "Hämarik".

1890. aastail puutus ta kokku poliitiliselt radikaalsete Tartu Ülikooli läti tudengitega, samuti Eduard Vildega (Kuningas 1979: 5). Kõik need motiivid ja mõjud, millega Rainis kokku puutus, ilmnevad tema töödes, nagu on märkinud läti kirjandusuurija Voldemars Kalpinš. Sageli on need motiivid esitatud läti rahvalaulu daina vormis.

\section{Rainis eesti keeles}

Olulisemaid Rainise töid hakati eesti keelde tõlkima alles 1920. aastail. Senini oli ilmunud üksikuid luuletusi perioodikas. Rainis oli juba umbes 60aastane, kui 1928. aastal ilmus eesti keeles tema tragöödia "Joosep ja tema vennad" 
(“Jāzeps un viṇa brāli”, 1919). 1930. aastad olid tõlgete osas üsna tagasihoidlikud, nagu ka 1970. ja hilisemad aastad on olnud. Ajakirjas Looming ilmus siiski aeg-ajalt põhjalikumaid Rainise tutvustusi. Valdemar Damberg keskendus Rainisele kui klassitsistliku kirjanduse loojale, kes on kirjutanud ka realistlikke teoseid, olles naturalismi ja sümbolismi vahelüliks. Rainise kui kirjaniku ja tõlkija kujunemisele avaldas tugevat mõju Peterburi ülikool, kus ta õppis küll õigusteadust aastail 1884-1888, kuid samal ajal hakkas ta tõlkima maailmakirjanduse klassikuid, nagu Goethe, Ovidius, Catullus, Sappho, Puškin jt. Damberg nimetab tol ajal ülikoolis valitsenud õhkkonda "tormi ja tungi" ajajärguks, mis on mõjutanud Rainise kogu edasist elu ja loomingut. (Damberg 1925: 704) Edasine elu oli kirjanikul tugevalt seotud poliitilise tegevusega Läti sotsiaaldemokraatide ringkonnas, kus ta toimetas kõigepealt ajalehte Dienas Lapa ning võitles pidevalt Tsaari-Venemaa poolt määratud karistustega, mis seisnesid peale lühiajalise vangistuse pikemaks ajaks maalt väljasaatmises Vjatka kubermangu (1899-1903). Olles kodumaalt pagendatud, tegeles Rainis intensiivselt tõlkimise ning kirjanikutööga. Sel perioodil tõlkis ta läti keelde Goethe "Fausti" (1898, vrd eesti k I osa 1920, tlk Anton Jürgenstein) ning kirjutas näidendi “Tuli ja öö” ja hulgaliselt revolutsioonilist luulet. Mart Pukits tõstab esile just "Fausti" tõlkimist: "See töö õnnestas tal [Rainisel] nii hästi, et ühe hoobiga ta nime tuttavaks tegi. Selle ajani oldi Läti keelt nii sõnavaeseks ja labaseks peetud, et sarnaste tööde tõlkimist täitsa võimata asjaks peeti. Rainis korjas kõik vana keelerikkuse kokku ja kus puudu tuli, lõi ta uued sõnad. Sellega oli Rainis võimatuse võimalikuks teinud ja luulele uue tee murdnud. Ka algupäraseid laulusid kirjutas ta" (Pukits 1911: 17).

Valdemar Damberg rõhutas, et Rainise tulek kirjandusse langes väga intensiivsele perioodile nii kirjanduslikus kui ka poliitilises mõttes. Rainist iseloomustas Damberg kui kirjanikku, kes sai inspiratsiooni nii oma kaasaegsest Euroopa kultuurist kui ka klassikutelt. Rainis oskas oma teosetes kokku sulatada modernistlikud stiilid nagu impressionism, klassitsistliku vormilahendusega. Oma näidendites kasutas ta palju mütoloogiat ja rahvaluulet, seejuures mitte ainult läti oma, vaid laenas motiive teisteltki rahavastelt ning kirjanikelt (Damberg 1925: 705-707).

Rainise kaalukaim loomepärand on kindlasti tema draamalooming, kus ta kasutab samuti sümbolite keelt: "Rainise iseäralduseks on väljendada oma tundeid ja mõtteid võrdluskujudes ja sümbolites, mis tihenedes saavad mõne teatava aate personifitseeritud kandjateks, kes siis ühenduses draama tegevuskavaga satuvad konflikti oma ümbruse ja kaastegelastega... [---] Kõigis oma dramaatilistes teostes kasutab ta ohtralt rahvaluule aineid, muinaslugusid ja ajaloolisi episoode ning oskab neid nii osavalt siduda ajakohase meeleoluga ja 
poliitiliste momentidega, et nad sageli, riivates ühtlasi ühiskondlikke probleeme, omavad aktuaalse põnevuse, kuigi nende kandvaks põhimotiiviks on üldrahvalik element. Sellega on ka seletatav Rainise suur populaarsus kõikide rahvakihtide seas" (Pukits 1929: 1179).

Pukitsa käsitlus lähtub 20. sajandi alguse revolutsioonilisest situatsioonist, millest ei jäänud puutumata ka kirjandus. Nüüdseks võib öelda, et Rainise tekstide tõlkimine eesti keelde on olnud edukas ning tema teoste vastuvõtt 1950., 1960. ja 1970. aastatel oli samuti väga hea. Eriti käib see näidendi "Puhu, tuul!" ("Pūt, vējiṇi!", 1914) kohta, mille lavastas Ants Lauter 1952. aastal Vanemuises, Aleks Sats 1966. aastal Viljandi Ugala teatris ja 1972. aastal Kaarin Raid Pärnu teatris. 1966. aastal lavastas Epp Kaidu Rainise näidendi “Joosep ja tema vennad" ("Jāzeps un viṇa brāḷi", 1919) Vanemuises ning 1967. aastal lavastati Eesti Televisioonis “Tuli ja öö” ("Uguns un nakts”, 1905, lavast 1911).

\section{Folkloorsed motiivid uues kontekstis}

\section{“Tuli ja öö"}

2015. aastal lavastati Läti Rahvusteatris Rainise värssnäidend “Tuli ja öö” ("Uguns un nakts"), mis ilmus 1905. aastal kohe pärast seda, kui autor naases pagendusest Slobodskis. ${ }^{3}$ Lavale jõudis teos esimest korda siiski alles 1911. aastal. Selles draamas kasutab Rainis rahvaluule motiive, tegelased pärinevad Pumpursi eeposest "Lačplēsis". Alapealkiri Rainise teosel on "Muistne laul uutes helides”, st Rainis määratles oma draama juba selle sünni ajal uuenduslikuks, kuigi pealtnäha oleks nagu tegu Lačplēsise dramatiseeringuga. Omal ajal lavastati ja tõlgendati seda kui vabadusvõitluse ja eriti just töölisklassi võitluse ideid kujutavat teost. Seda on peetud sümbolistlikuks ja impressionistlikuks draamaks ning arvestades aega, mil ta sündis, on sel ka tugev ideoloogiline taust.

Rainis kasutab rahvaluule motiive, kuid töötleb neid ümber vastavalt oma kaasaegsele kontekstile. Draama "Tuli ja öö” (1907) on tegelikult läti eepose "Karutapja" uus variant, kus kunagine rahvuslik legend saab uue tähenduse. Samas juhib Mart Pukits tähelepanu ka Rainise loodud (rahvuslike) sümbolite dünaamilisusele: "Karumurdja suurema vastase Musta rüütli kujuga ei mõtle luuletaja mitte üksi võõraid sissetungijaid, vaid ka kulla ehk raha võimu [---] Karumurdja ja rüütli näol põrkavad kokku ürgne ja praegune ilmakord või vana ja uus kultuur: võitlevad vastamisi tuli ja öö. Viimase võit on siiski ajutine, luuletaja laseb loota, et lõplikuks võitjaks tuleb Spīdola abiga Karumurdja, ja siis teostub autori lemmikaade uuest ühiskonnast, mil enam ei võitle rahvas 
rahva vastu, vaid kõik üheskoos pimeduse vastu, kuni must võim murtakse jäädavalt” (Pukits 1929: 1181).

2015. aasta Viestur Kairishi Läti Rahvusteatri lavastuses pole vanad ideoloogiad enam olulised, siis tulevad mängu uued kostüümid, Wagneri muusika ja uue lavastaja kultuurimälu. Ometi on seegi lavastus tugevalt sümbolistlik, kandes Rainise ideed, et sümbol on oma olemuselt polüsemantiline ning selle tähendus võib näidendi jooksul mitu korda muutuda.

\section{"Kuldratsu"}

Esivanemate pärandit on Rainis kasutanud oma näidendis "Kuldratsu" ("Zelta zirgs”, 1909), kus on äratuntav paljude rahvaste muinasjuttudest pärit motiiv kolmest vennast, kellest üks, kes on kõige rumalam, kuid samas kõige heatahtlikum, kasutab kavalust ja oma sõpru ning päästab lõpuks kuningatütre. Tasuks saab ta kuningatütre omale naiseks ning lisaks veel terve kuningriigi valitseda.

Tuleb nõustuda läti uurija Andre Šedriksiga, kes kirjutab: Mis iganes ideoloogiline interpretatsioon ka Rainise töödele anda, tema elu oli täielikult oma rahva vabanemisele pühendatud (Šedriks 1979: 40). Siia võiks vaid lisada, et see ei kehti ainult läti rahva kohta, vaid ka teiste rahvuste ja inimeste kohta, sest Rainise tekstid on üldmõistetavad ja üldinimlikud, tuginedes erinevatele müütilistele ja rahvaluule motiividele, mis teevad need tekstid mõnevõrra esoteeriliseks ning samal ajal huvitavaks ja põnevaks.

Mis puutub eesti-ainelistesse mõjudesse Rainise töödes, siis mainib Šedriks neid seoses näidendiga "Kuldratsu" (Šedriks 1979: 43-44). Voldemars Kalpinš kirjutab, et Rainise näidendi "Kuldratsu” (1909) idee pärineb Kreutzwaldi muinasjutust "Kuidas üks kuningatütar seitse aastat oli maganud". Samal ajal on samasugune lugu printsessist, kes magab klaasmäel, väga tuntud Põhja-Euroopas (Šedriks 1979: 42). See fakt ei ühenda mitte ainult eesti ja läti folkloori, vaid asetab need ka Euroopa konteksti ning osutab Euroopa rahvaste omavahelistele suhetele. Eesti imemuinasjuttude tüübiantoloogia andmeil on "Kuningatütar klaasmäel" jututüüp levinud erinevate variantidena just Lõuna-Eestis ja Setumaal ning on samas rahvusvaheliselt väga tuntud, vanim teadaolev kirja pandud klaasmäe vallutamise lugu pärineb 16. sajandi Taanist, see on motiiv Siegfriedi ja Brünhildi loost (Järv \& Kaasik \& Toomeos-Orglaan 2014: 641). Kreutzwaldi muinasjutt on üks mainitud jututüübi variante (ibid.). August Annisti kommentaaridest Kreutzwaldi kohta saab teada, et arvatavasti laenas Kreutzwald seitse aastat kestnud une motiivi "Lumivalgekese" või "Okasroosikese" jutust (Kreutzwald 2006: 448). 


\section{"Puhu, tuul!"}

Rahvaluulele veelgi lähemal on eepilis-lüürilised näidendid, mida autor isegi nimetab lauludeks. Sinna alla kuulub liivi rahvalaulu motiivi kasutav "Puhu, tuul!" ("Pūt, vējiṇi!", 1914) ja "Mängin, tantsin" ("Spēlēju, dancoju”, 1915, lavast 1921).

Neist Rainise töödest võib leida teisigi eesti folkloorist pärinevaid motiive. Tähelepanuväärne on, et kõik need motiivid on üsna traagilised ja dramaatilised. Voldemars Kalpinš ja Oskar Kuningas on analüüsinud ja kirjeldanud neid motiive, mis pärinevad eeposest "Kalevipoeg” ja mütoloogilisest jutustusest "Koit ja Hämarik". On teada, et Rainis oli lugenud "Kalevipoega" saksa keeles ning tõlkinud ka mõned laulud saksa keelest läti keelde. Sarnased on orjatüdruku motiiv “Kalevipojast” ja Baiba tegelaskuju näidendis "Puhu, tuul!". Mõlemad tegelased olid orvud ning pidid tegema rasket tööd võõras peres.

Orvu-motiiv osutab ka mitmetele variantidele Tuhkatriinu-loost, mis on levinud üle maailma, sh kombineeritult teiste jututüüpidega (Järv \& Kaasik \& Toomeos-Orglaan 2014: 631). Eesti kirjanduses on tuntud Kreutzwaldi "Tuhka-Triinu", mille arvatavateks eeskujudeks on olnud Ch. Perrault' ja vendade Grimmide lood (samas) Samas on huvitav, et Rainis kasutab ka teist motiivi "Kalevipojast" - see on Saarepiiga motiiv. Saarepiiga oli neiu, kes elas saarel ning kui ta kohtus seal Kalevipojaga, leidis aset traagiline armastuslugu, mille tagajärjel Saarepiiga hüppas merre ja uppus. Johannes Semper on analüüsinud rahvaluule motiive "Kalevipojas" ning tema näeb paralleele "Kalevipoja" ja soome eepose "Kalevala" vahel: end uputades enesetapu sooritava neiu motiiv kordub "Kalevalas" mitu korda. Näiteks Kullervo loos, kus Kullervo kohtab oma rännakul ilusat neidu ning vägistab ta. Järgmisel päeval selgub, et tüdruk oli Kullervo õde, mispeale neiu end uputab. Semperi järgi toimus intsest ka Kalevipoja ja Saarepiiga vahel. Teine traagiline episood "Kalevalast", millest Kreutzwald oli inspireeritud, on lugu Väinamöisest ja Ainost. See kurb armastuslugu lõpeb Aino merre uppumisega. On hästi teada fakt, et "Kalevala" mõjutas Kreutzwaldi - ta kirjeldas neid mõjusid oma kirjades sõpradele (Semper 1997: 100-104). Samal ajal on kõik need motiivid hästi teada Euroopas ning need on eksisteerinud rahvuskirjandustes väga kaua (näiteks Ophelia Shakespeare'i "Hamletis"). Rainise originaalsus seisneb selles, et ta ühendab Tuhkatriinu-motiivi traagilise uppunud neiu motiiviga. Traditsiooniliselt on Tuhkatriinu-lool õnnelik lõpp, kuid eesti folklooris see alati nii ei ole (näiteks Tiina Kitzbergi “Libahundis"). Tundub, et Rainis ühendab Tuhkatriinu motiivi traagilise Saarepiiga motiiviga või võib-olla ka Aino-looga. Teine traagiline, kuid samas ülev motiiv, mille jälgi võib Rainise töödest leida, on müütiline muistend "Koit ja Hämarik". See on legend päikesetõusust ja -loojangust suvise pööripäeva ajal, mil Põhjamaades on valged ööd ning legendi järgi sulavad päev 
ja öö suudlustes üheks. See on Faehlmanni lugu, mis on inspireerinud skulptor August Weizenbergi skulptuuride loomisel, mis omakorda inspireerisid Rainist. See päikesetõusu ja -loojangu personifikatsioon kordub ka Rainise näidendis "Puhu, tuul!", nagu on märkinud Oskar Kuningas (Kuningas 1969). Kuigi päikesetõusu motiiv on hästi tuntud juba antiigist peale (Kreeka mütoloogiast on tuntud naisjumalused Eos ja Selene ning Rooma mütoloogiast Aurora), erinevad need armastuslood Faehlmanni kirjutatud loost. See traagiline situatsioon muudab loo ülevaks ning näib, et köidab ka Rainist.

Legendi järgi kohtuvad Koit ja Hämarik üks kord aastas ning nende õnnetundega ühineb kogu loodus. See sügav armastus liigutas Eesti jumalust, keda kutsutakse Vanaisaks. Seda nime võiks mõista kui Igavikku või Kõiksust. Igavik küsis Koidult ja Hämarikult, kas nad tahaksid abielluda ning jääda igavesti kokku, kuid Koit ja Hämarik palusid Igavikul mitte rikkuda nende rõõmu ning palusid luba jääda igaveseks ajaks pruudiks ja peigmeheks. See on platooniline armastuslugu, kus Koitu ja Hämarikku ühendavad vaid suudlused. Kuid samas on see ka väga kirglik lugu, kus kirg ei jahtu iialgi ning seesama situatsioon kordub igal aastal.

Rainise näidendis "Puhu, tuul!" on sarnane situatsioon Baiba ja Uldise vahel: kirg muutub aina tugevamaks ja tugevamaks ning kõik lõpeb sellega, et Baiba annab Uldisele hüvastijätusuudluse ning hüppab vette.

Seda Tuhkatriinu-lugu on läti kirjanduses erinevalt mõtestatud ja interpreteeritud, rahvalaulumotiividel põhinev populaarne laul "Puhu, tuul" elab oma elu laulupidudel (vt Kalnačs 2016: 93-95).

\section{“Joosep ja tema vennad"}

1966. aastal lavastas Epp Kaidu Vanemuises Rainise piibliainelise näidendi "Joosep ja tema vennad" ("Jāzeps un viṇa brālī", 1919). Selles teoses on Rainis üsna algtekstitruu, kuid Piibli legendi taga on mõeldud omaenda rahva saatust. Benedikts Kalnačs on märkinud, et 1920. aastatel suurenes Eestis ja Lätis tähelepanu filosoofilistele teemadele, mida esindavad mainitud Rainise näidend ning Tammsaare "Juudit" (1921). Rainise teksti on tõlgendatud seejuures tema enda saatusega seotult ning pikaaegse eksiilis viibimisega poliitilistel põhjustel. (Kalnačs 2016: 96-100)

2005. aastal toimus Läti Rahvusteatris Rainise näidendi "Joosep ja tema vennad" uuslavastuse esietendus, lavastajaks oli Māra Kimele. Selles lavastuses tõuseb esikohale kodu sümbol, samuti suhted "omade" ja "võorraste" vahel, mida näidendis annavad edasi Joosepi ja tema vendade pingelised suhted (Kalnačs 2016: 91). 
Vähemalt sama oluline roll kui kirjandusel on identiteetide kujundamisel olnud ka kõikvõimalikel müütidel, mis võivad kultuuris eksisteerida iseseisvalt või ilukirjandusse põimitult. Kirjanduses leiduvad Piibli müüdid esindavad kultuuris valdkonda, kus pühajutt on juba ilmalikuks saanud (vt Puhvel 1996: 10). Piiblimüüdid ilukirjanduses tekitavad olukorra, mis ei eelne kirjanduse eksisteerimisele, vaid ajajärgu, kus mütoloogiline tendents kultuuris tingimusteta domineerib. See on periood, mil kultuurikandjad kirjeldavad iseendale oma kultuuri mütoloogia alusel loodud metakeele terminites. (Lotman 1991: 318) Nii nagu paljud autorid, kasutab ka Rainis motiive Piiblist, tõlkides neid müüte ja motiive oma rahvale arusaadavaks ning selle kaudu saab neist esmapilgul kaugetest müütidest oma kultuuri osa, sest need vanad müüdid räägivad siis juba oma rahva lugu. Rainise teoste kaudu räägivad nad kõigepealt läti rahva saatusest, kuid tänu kultuurilisele lähedusele on need mõistetavad teistelegi sarnase saatusega rahvastele.

\section{Kokkuvõtteks}

Läti kirjanik Rainis on lisaks läti rahvaluulele kasutanud oma teostes Piibli legende ning üle maailma tuntud muinasjutte. Ta on põiminud oma teostesse mitmeid legende ja vanu lugusid, andes neile uusi tähendusi ning tõlgendusi, sest kõik need kasutatud motiivid astuvad Rainise teostes dialoogilisse suhtesse teiste "võõraste" motiividega või metakeelega. Rainise looming on näide sellest, kuidas toimub kultuuriteksti tõlkimine oma kultuuri, kuidas folkloor ja vanad müüdid on kasutust leidnud ilukirjanduses ning sealt levinud edasi kultuuri laiemalt, saades uues kontekstis uusi tähendusi. Kasutades vanu sümboleid ja motiive, mis on pärit “võõrastest" kultuuridest, ilmneb Rainise loomingu põhjal, kui mitmekesine ja dialoogiline võib olla kirjanduslik kommunikatsioon, millest võtavad osa peale autori, teose ja lugeja veel terve rida metakommunikatsioonis osalejaid, loomaks iga teose ümber originaalse tähendusvälja. Selle tulemusena ei sõltu loodud kirjandusteosed nii palju muutuvatest ideoloogiatest, vaid pigem muutuvast (ajaloolisest) kontekstist, kuigi neid on kasutatud erinevate ideoloogiate teenistuses. 


\section{Kommentaarid}

1 Artikli valmimist on toetanud Eesti Haridus- ja Teadusministeerium (IUT 18-4) ja Eesti-uuringute Tippkeskuse (CEES) projekt TAU 16078.

2 Artiklis on kasutatud kirjanikunime Rainis, mida juba kirjanik ise on kasutanud rohkem kui kodanikunime Jānis Pliekšāns (1865-1929).

3 Pärast 1905. aasta revolutsiooni emigreerus Rainis koos oma abikaasa Aspasiaga Šveitsi, kus elas ja kirjutas 1920. aastani, mil naasis iseseisvasse Läti Vabariiki.

\section{Kirjandus}

Calinescu, Matei 1987. Five Faces of Modernity. Modernism, Avant-Garde, Decadence, Kitsch, Postmodernism. Durham: Duke University Press.

Damberg, Valdemar 1925. Jaan Rainis. Looming 9, lk 703-708 (https://www.digar.ee/ viewer/et/nlib-digar:44378/16057/page/32 - 6. mai 2019).

Egalāja-Kristsone, Eva 2009. Symbols Reflecting the Rising Spirit of Society in Rainis' Poem Ave Sol! and Gustav Suits' Poetry. Mihkelev, Anneli (toim). Turns in the Centuries, Turns in Literature. Comparative Approach to Estonian and Latvian Literatures in a European Context. Tallinn: Underi ja Tuglase Kirjanduskeskus, lk 52-65.

Järv, Risto \& Kaasik, Mairi \& Toomeos-Orglaan, Kärri 2014. Eesti muinasjutud I : 2. Imemuinasjutud. Tartu: Eesti Kirjandusmuuseumi Teaduskirjastus.

Kalnačs, Benedikts 2016. 20th Century Baltic Drama: Postcolonial Narratives, Decolonial Options. Bielefeld: Aisthesis Verlag.

Kreutzwald, Friedrich Reinhold 2006. Eesti rahva ennemuistsed jutud. Tallinn: Koolibri.

Kuningas, Oskar 1969. Eesti motiive näidendis “Puhu, tuul!”. Edasi 228, 28. september, lk 3.

Kuningas, Oskar 1979. Rainis ja Eesti. Edasi 226, 29. september, lk 5.

Lange, Anne (koost) 2002. Six Estonian Poets in Translations of Ants Oras. Kuus Eesti luuletajat Ants Orase tôlkes. Tallinn: Tänapäev.

Lotman, Juri 1991. Kultuurisemiootika. Tekst - kirjandus - kultuur. Tallinn: Olion.

Lotman, Juri 1999. Semiosfäärist. Tallinn: Vagabund.

Lotman, Juri 2001. Kultuur ja plahvatus. Tallinn: Varrak.

Pilv, Aare 2009. The Idea of Homeland in the Poetry of G. Suits (with some shortcuts to Rainis). Mihkelev, Anneli (toim). Turns in the Centuries, Turns in Literature. Comparative Approach to Estonian and Latvian Literatures in a European Context. Tallinn: Underi ja Tuglase Kirjanduskeskus, lk 66-77. 
Puhvel, Jaan 1996. Võrdlev mütoloogia. Tartu: Ilmamaa.

Pukits, Mart 1911. Pilk Läti kirjandusse. Eesti Kirjandus 1. Kuues aastakäik, lk 10-25.

Pukits, Mart 1929. J. Rainis ja tema looming. Looming 10, lk 1172-1183 (https://www. digar.ee/viewer/et/nlib-digar:44712/16098/page/5 - 3. mai 2019).

Rainis, Janis 1965. Valitud teosed II. Aben, Karl (koost). Tallinn: Eesti Raamat.

Semper, Johannes 1997. Kalevipoja rahvaluulemotiivide analüüs. Tallinn: Olion.

Šedriks, Andre 1979. Introduction to The Golden Steed. Straumanis, Alfred (toim). The Golden Steed. Seven Baltic Plays. Illinois: Waveland Press, lk 39-49.

Torop, Peeter 1999. Kultuurimärgid. Tartu: Ilmamaa.

\title{
Summary
}

\section{From folklore to literature: Variation in Rainis' literary works}

\author{
Anneli Mihkelev \\ Senior Research Fellow \\ School of Humanities, Tallinn University \\ anneli.mihkelev@tlu.ee
}

Keywords: cultural transformation, cultural translation, folklore and literature, folk motives, Latvian literature, modernism, symbolism

Rainis (Jānis Pliekšāns, 1865-1929) was a very famous Latvian modernist writer of the beginning of the 20th century. His literary works are connected with Estonian culture via different motifs. Rainis' texts, translated into Estonian, contain indications of double cultural translation, and thus constitute a very interesting case in European culture. The article analyses Rainis' plays "Uguns un nakts" (Fire and Night, 1905), "Zelta zirgs" (The Golden Steed, 1909), "Pūt, vējiṇi!" (Blow, Wind! 1914), and "Jāzeps un viṇa brāḷi”" (Joseph and His Brothers, 1919).

According to Latvian and Estonian researchers, Rainis' play titled "The Golden Steed" drew on Friedrich Reinhold Kreutzwald's fairy tale about a princess who slept for seven years. On the other hand, a story about a princess who slept on a glass mountain is well known in Northern Europe. Rainis also used motifs from the Estonian epic "Kalevipoeg" (Kalev's Son) and the mythological story "Koit ja Hämarik" (Dawn and Dusk). The motif he used in his drama "Blow, Wind!" is the orphan motif from "Kalevipoeg". Both the slave girl from the latter and Baiba from Rainis' drama were orphans and had to work hard for their stepfamily. The orphan motif certainly points to several variants of the Cinderella story which have spread all over the world. 
The myth of Dawn and Dusk is a story by an Estonian writer, Friedrich Robert Faehlmann (1798-1850), which inspired both sculptor August Weizenberg and Rainis in the creation of their characters. The personification of the motifs of sunrise and sunset are repeated several times in Rainis' play "Blow, Wind!". There is a situation involving Baiba and Uldis, in which their passion becomes stronger and stronger, while it all ends with a farewell kiss from Baiba and her jumping into the water.

Estonian writer Johannes Semper has analysed folk motifs in the "Kalevipoeg" and he sees its parallels with the Finnish epic "Kalevala" in this regard: the motif of the maiden who commits suicide by drowning is repeated several times in the latter. This reminds us of the story of Kullervo, who met a nice maiden on his travels and raped her. Next day it turned out that the girl was Kullervo's sister, and the maiden drowned herself. According to Semper there were more tragic stories which implicate the epics: the story of Kalevipoeg and Saarepiiga in the epic "Kalevipoeg" and the story of Väinämöinen and Aino in the epic "Kalevala". All these motifs are well known in Europe and have existed in national literatures for a very long time (cf. Ophelia in Shakespeare's "Hamlet").

Rainis' drama "Fire and Night" (1905), based on the Latvian epic "Lāčplēsis" (Bear Slayer, 1888), is probably the most significant symbolic work in Latvian literature. The drama demonstrates how literary symbols work in culture where the fundamentally new is created, and it is a process which contains the moment of explosion according to semiotician and literary scholar Yuri Lotman. All these symbols are dynamic, and it depends on the context and on the readers how these literary figures and texts are interpreted. Rainis' symbols are polysemantic and one and the same symbol can change meanings several times within a play.

The drama "Joseph and His Brothers" (1919) is based on a biblical myth and it is a neo-mythological literary work and also a cultural translation and transformation. The Bible functions as a metatext in Rainis' text and in Latvian culture describing, via auto-communication, the Latvian culture itself. The Estonian translation functions in a similar way in Estonian culture because Latvian and Estonian cultural contexts are similar.

Anneli Mihkelev kaitses doktorikraadi 2005. aastal Tartu Ülikoolis semiootika ja kulturoloogia erialal monograafiaga "Vihjamise poeetika". Töötab Tallinna Ülikooli Humanitaarteaduste instituudis vanemteadurina, on seotud Tallinna Ülikooli kultuuridevaheliste uuringute tippkeskuse ja Eesti-uuringute Tippkeskusega. Peamised uurimisvaldkonnad hõlmavad eesti ja balti kultuuri, võrdlevat kirjandusteadust, allusioonide toimimist kirjanduses ja kultuuris. Neil teemadel on ta avaldanud mitmeid artikleid nii Eesti kui ka rahvusvahelistes väljaannetes. 
Anneli Mihkelev has a PhD in Semiotics and Cultural Studies from the University of Tartu with the monograph Vihjamise poeetika (The Poetics of Allusion). She works as Senior Research Fellow at Tallinn University, and is currently connected with the Centre of Excellence in Intercultural Studies and the Centre of Excellence in Estonian Studies. Her fields of research include Estonian literature, allusions in literature and culture, and comparative literature (mainly Baltic literatures). She has published articles on these topics in international and Estonian publications.

anneli.mihkelev@tlu.ee 